Wang, X. \& Lázaro Gutiérrez, R. (2021). Healthcare interpreting: filling the training gap to achieve required competences. Current Trends in Translation Teaching and Learning E, 8. 124 - 153. https://doi.org/10.51287/cttle20215

\title{
HEALTHCARE INTERPRETING: FILLING THE TRAINING GAP TO ACHIEVE REQUIRED COMPETENCES
}

Wang Xi

Raquel Lázaro Gutiérrez

University of Alcalá

\begin{abstract}
At a time when societies are becoming more demographically diverse, the employment of professional interpreters to facilitate communication between healthcare practitioners and patients is of great benefit to both patients and the healthcare system. However, as an emerging profession, the definition of the professionalism of practitioners is not very clear, and there are gaps in the training they receive. Taking this into account, this article is mainly divided into two sections. Firstly, we analyse the models about interpreting competence made by different researchers, find their respective characteristics, and integrate them to obtain a model of competence applicable to healthcare interpreting. Secondly, we take Spain as an example of a recent immigration country with a long history of interpreting training. Based on the above mentioned
\end{abstract}


Wang, X. \& Lázaro Gutiérrez, R. (2021). Healthcare interpreting: filling the training gap to achieve required competences. Current Trends in Translation Teaching and Learning E, 8. 124 - 153. https://doi.org/10.51287/cttle20215

competence model we have analysed syllabi of all formal training courses on interpretation and those representative informal training ones to explore whether they can meet student training needs regarding the requirements of stakeholders. The research results show that due to the limited diversity of language combinations, there is a shortage in thematic knowledge, terminology referring to specific cultural aspects corresponding to each language and the development of corresponding strategic competence. Furthermore, the development of the healthcare (thematic) subcompetence seems to be still an unfinished business. In order to fill these gaps, we have put forward recommendations to the establishment of a complete training system for the long run, as well as a fast-reacting and more feasible option that can be implemented at an earlier stage.

Keywords: healthcare interpreting, interpreting competence, training gap

\section{INTRODUCTION}

With the increase in population exchanges on a global scale and the development of immigration policies all around the world, the demographic composition of society is becoming increasingly diverse, which leads to closer interaction between people with very different cultural and linguistic profiles. Under this context, a number of professions 
Wang, X. \& Lázaro Gutiérrez, R. (2021). Healthcare interpreting: filling the training gap to achieve required competences. Current Trends in Translation Teaching and Learning E, 8. 124 - 153. https://doi.org/10.51287/cttle20215

arise to respond to these new social demands. Among them is that of the public service interpreter, which is dedicated to facilitate communication between people who do not master the languages of a host country and its native service providers, with the purpose of bridging linguistic barriers so that each party can achieve their goals in the interaction.

Receiving adequate medical care is one of the fundamental human rights. In Spain, every individual has the right to access healthcare in equal conditions, and different administrative mechanisms exist to fund healthcare assistance for foreign patients, such as agreements amongst countries, social security payments, special agreements for refugees, asylum seekers or minors, regional funding plans for immigrants who do not work in Spain, private insurance policies which cover expenses related to the access to public healthcare services. The quality of treatment has an impact on health status and quality of life (Regata Cuesta, 2017; Borrell et al., 2018). Therefore, in the healthcare field, the availability of an interpreter is essential and necessary. For patients, assistance by a professional interpreter allows them to get a better understanding of the information offered by the physician and to raise their level of participation in the interaction (Lázaro Gutiérrez, 2012), which is considered essential to obtain a correct diagnosis, as 
Wang, X. \& Lázaro Gutiérrez, R. (2021). Healthcare interpreting: filling the training gap to achieve required competences. Current Trends in Translation Teaching and Learning E, 8. 124 - 153. https://doi.org/10.51287/cttle20215

well as appropriate treatments. In addition, interpreters' intervention can positively influence clinical outcomes (Hsieh, 2016). From the point of view of the healthcare system, interpreting has been related to the reduction of care times, readmission rates, and a reduced application of unnecessary tests (NSW, 2017). On the contrary, the involvement of a non-professional "interpreter" (understood as someone without training in interpreting) cannot guarantee the aforementioned conveniences, and will even cause negative effects in different phases of communication (Cox \& Lázaro Gutiérrez, 2019).

Despite the fact that more and more people are becoming aware of the importance of counting on professional interpreters, the role of communication facilitator in the healthcare environment is currently played by those accompanying the user and by fellow healthcare personnel who know the languages, especially in countries with a shorter immigration history, as is still the case in Spain. As is well known, linguistic knowledge is not the only competence interpreters must possess. Interpreting, as a profession, implies the need to achieve professional competences of different nature, and working in a particular field requires, thus, a series of specific skills and knowledge in consonance with the characteristics of the setting in which interpreting is performed. Although in the early 
Wang, X. \& Lázaro Gutiérrez, R. (2021). Healthcare interpreting: filling the training gap to achieve required competences. Current Trends in Translation Teaching and Learning E, 8. 124 - 153. https://doi.org/10.51287/cttle20215

stage of the profession's development, the pioneering interpreters explored and learned on the progress (Baigorri, 2000), today, acquiring such skills and knowledge through adequate training and reinforcing them through professional practice can be considered the reasonable manner to become a competent interpreter (Hale, 2007; Crezee, 2013; Hsieh, 2016).

Building a solid training system is the most important and effective way to provide qualified interpreters to the market, as well as to promote the development of the profession. So what are the exact competences interpreters need? Can the existing training in healthcare interpreting meet the needs of stakeholders? Is there a solution that quickly responds to market demand? In the following pages, we will try to find answers to these questions.

\section{INTERPRETING COMPETENCE IN THE HEALTHCARE SETTING CONTEXT AND ISSUE IN QUESTION}

One of the purposes of specialized training is to address the development of professional competences by trainees, so, understanding which the components of such competences are is the precondition for the design of educational programs (Kelly, 2005; Angelelli, 2006). 
Wang, X. \& Lázaro Gutiérrez, R. (2021). Healthcare interpreting: filling the training gap to achieve required competences. Current Trends in Translation Teaching and Learning E, 8. 124 - 153. https://doi.org/10.51287/cttle20215

According to the European Qualifications Framework for Lifelong Learning, competence, in its general sense, refers to "the proven ability to use knowledge, skills and personal, social and/or methodological abilities, at work or study situations and in professional and personal development." (European Communities, 2008, p.11). Emphasis is placed on the practical ability to deploy skills, whereas, in the educational setting, the focus is also on gaining knowledge.

In the field of interpretation, the discussion on the skills and knowledge required by interpreters dates back to the 1930s. The pioneering studies (Sanz, 1931; Herbert, 1952; Walter Keiser, 1978) are characterized by their main focus on conference interpreting and the attention paid to physiological aspects and innate skills, such as good hearing, good breathing, quick reaction, etc.

In the 1990s, Gile (1995) developed an Effort Model from a cognitive approach, dividing the interpreting process into different phases, which require related skills. Since then, researchers started to focus on acquired skills, such as note-taking, synthesis and analysis techniques, and understanding of extralinguistic factors. 
Wang, X. \& Lázaro Gutiérrez, R. (2021). Healthcare interpreting: filling the training gap to achieve required competences. Current Trends in Translation Teaching and Learning E, 8. 124 - 153. https://doi.org/10.51287/cttle20215

In the new century, researchers' interest in proficiency is no longer limited to the interpreting activity itself, but begins to extend to upstream and downstream stages, taking into account external components. For example, the model proposed by Kina (2002), which was later modified and completed by Albl-Mikasa (2012), divides interpreting competence into six categories of skills and knowledge, depending on the phases of the interpreting activity (pre-process, peri-process, inprocess, post-process and para-process). In addition to the skills needed during the interpreting process, it also focuses on personal interaction, project management, client maintenance, and lifelong learning, factors closely linked to personal and professional development.

So far, it can be concluded that interpreting competence underwent an evolution from understanding the components in a linear relationship to building multidimensional models; from focusing on innate skills, to paying more attention to those that can be acquired by learning; from a general description of interpreting, to a multifaceted set of characteristics applied to different settings and modalities; and from focusing on the interpreting process itself, to considering multiple factors by treating interpreting as a complex and integral activity. These 
Wang, X. \& Lázaro Gutiérrez, R. (2021). Healthcare interpreting: filling the training gap to achieve required competences. Current Trends in Translation Teaching and Learning E, 8. 124 - 153. https://doi.org/10.51287/cttle20215

aforementioned studies, although most have conference interpreting as their primary research focus, are based on interpreting in general, and are, therefore, applicable to interpreting in the healthcare context.

Generally speaking, research dedicated to the interpreting competences required in public services (Pöchhacker, 2000; Abril, 2006; Corsellis, 2008; Remael et.al., 2018) and in the healthcare setting in particular (Blignault, 2009; Crezee, 2013) has emerged in the first two decades of the present century, coinciding with the time when the market demand for this type of service appeared, which also indicates the continuous specialization within the sector. Due to their interdisciplinary nature, the theoretical frameworks applied in research related to interpreting competence also cover intercultural communication (Kaczmarek, 2010, Peng, 2018).

Within this latter field, the object of study is generally not limited to interpreters, but widens to communication in foreign languages. Commonly, these studies put the focus on cultural and intercultural factors that may affect communication and specific knowledge in a particular field, while they do not pay so much attention to the techniques and strategies of interpreting itself. The focus on deontology and the psychological status of 
Wang, X. \& Lázaro Gutiérrez, R. (2021). Healthcare interpreting: filling the training gap to achieve required competences. Current Trends in Translation Teaching and Learning E, 8. 124 - 153. https://doi.org/10.51287/cttle20215

interpreters have also been lately considered by research within interpreting studies.

The aim or our study is twofold. On the one hand, we intend to integrate and further develop on previous studies in order to present a revised proposal of interpreting competence applied to the healthcare field. On the other hand, we will depart form this proposal to review current training offers in order to verify whether training and market needs are met. For the purpose of this study, interpreting competence is understood as an integral system composed of several subcompetences, following Kelly's (2002) and Abril's (2006) research. In particular, interpreting competence is broken down into six subcompetence areas, grouped into two blocks: interpreter's competences and interpreting competences.

Interpreter's competences refer to relatively generic skills and knowledge, linked more to the interpreter as a subject than to interpreting as a process. In this block the professional subcompetence is included, which involves but is not limited to work management, mastery of instrumental resources, collaboration and ability to work in a team, the habit of maintaining lifelong learning, deontological knowledge, and psychophysiological subcompetence. The interpreting competence block deals, on the other hand, with the knowledge and 
Wang, X. \& Lázaro Gutiérrez, R. (2021). Healthcare interpreting: filling the training gap to achieve required competences. Current Trends in Translation Teaching and Learning E, 8. 124 - 153. https://doi.org/10.51287/cttle20215

skills required for the interpreting act itself, and is made up of the linguistic subcompetence, cultural and intercultural subcompetence, strategic subcompetence, as well as health-related thematic subcompetence, which includes medical knowledge and knowledge of the health system, in addition to mastery of specific terminology. In this vein, in syllabi, the courses dedicated to the development of the subcompetences of the first block must always be present, while those of the second block should vary according to the given language combinations and fields.

\section{TRAINING IN HEALTHCARE INTERPRETING}

Our study considers the Spanish situation. Although interpreting training started relatively early in Spain, immigration is more recent than in other Western countries. Training in public service interpreting, though, and, in particular, healthcare interpreting are still at an initial stage. In this section we will approach the training offer in healthcare interpreting provided both at a formal university level (programs approved by the Spanish Ministry of Education), and an informal level, applying our healthcare interpreting competence model as the frame of reference and analysis. 
Wang, X. \& Lázaro Gutiérrez, R. (2021). Healthcare interpreting: filling the training gap to achieve required competences. Current Trends in Translation Teaching and Learning E, 8. 124 - 153. https://doi.org/10.51287/cttle20215

\subsection{Formal Training}

In order to select and determine the research objects, we searched the list QEDU $^{1}$ using a series of keywords related to interpreting training (interpretación; traducción; mediación; comunicación intercultural; interlingüística), and removed from the results obtained the items that only focused on translation, those designed for special models such as sign language, and languageunrelated courses, such as music performance majors, etc. In total, 29 undergraduate and 14 master's degrees which included a subject-matter in interpretation could be found in the Spanish university system ${ }^{2}$. Then all of the syllabi have been analysed and when the name of a course did not clearly indicate the content taught, the course plans were reviewed to confirm their focus and scope.

Through this study, it can be seen that all of those degrees contained courses dedicated to the development of the strategic subcompetence. Specifically, each program provides one to 12 courses of four to six ECTS respectively that include

\footnotetext{
${ }^{1}$ What to study and where to study at university, provided by the General State Administration.

2 The course contents and the linguistic offer may have changed. All data mentioned in this section are taken from the academic year 2019-2020.
} 
Wang, X. \& Lázaro Gutiérrez, R. (2021). Healthcare interpreting: filling the training gap to achieve required competences. Current Trends in Translation Teaching and Learning E, 8. 124 - 153. https://doi.org/10.51287/cttle20215

training in strategies as one of their main objectives. Regarding interpreting modalities, liaison interpreting is the less frequent type offered as an independent course, as it is only present as such in 13 programs distributed among eight universities. In the other cases contents about liaison interpreting are incorporated into courses about "general interpretation techniques" or "initiation to interpretation", which implies a shorter offer in teaching hours. Liaison interpreting is also present in the first few classes of the consecutive interpretation courses as introductory content.

On the other hand, the offer of courses aimed at the consecutive and simultaneous modality increases significantly. In general, each one occupies about 30 $\%$ to $40 \%$ of the total teaching hours allocated to interpretation, except in programs that do not distribute the credits according to interpreting modalities. This reflects that, considered as a whole, the training provided in these programs to develop the strategic competence seems to be adequate. However, the focus of teaching activities remains on the two modes that are most used in conference interpreting, and the bilateral mode, the one commonly used in healthcare interpreting, is often considered a conduit to "the real world of interpreting" and does not receive sufficient attention. 
Wang, X. \& Lázaro Gutiérrez, R. (2021). Healthcare interpreting: filling the training gap to achieve required competences. Current Trends in Translation Teaching and Learning E, 8. 124 - 153. https://doi.org/10.51287/cttle20215

The professional subcompetence has also been very much addressed in syllabi, as $93 \%$ of the programs offer a course on general terminology, whereas the percentage of courses about information mining and technology, and instrumental competence (understood as the use of interpreting professional tools, such as booths, and procedures, such as the different interpreting modalities) are $76 \%$ and $79 \%$ respectively. In addition, $65 \%$ of the degrees have courses on career development. Among all the aspects of this category, deontology receives the least attention, as the universities that implement such courses do not reach $30 \%$.

As for linguistic subcompetence, 21 of the 29 programs offer two to four courses in A language and more than four in B language. This shows that the emphasis on the two languages can basically be balanced. In terms of language options, all of those programs give preference to English, followed by European languages such as French, German, Greek and Italian. The most frequently non-European language is Arabic ${ }^{3}$.

\footnotetext{
3 The above six languages are the most frequently covered in all programs, among which Greek, Italian and Arabic are usually taught as $\mathrm{C}$ language.
} 
Wang, X. \& Lázaro Gutiérrez, R. (2021). Healthcare interpreting: filling the training gap to achieve required competences. Current Trends in Translation Teaching and Learning E, 8. 124 - 153. https://doi.org/10.51287/cttle20215

With regard to the thematic subcompetence, the most covered areas by these 29 programs are law and economics, localization, and audiovisual translation. There is a main focus on translation and interpretation is relegated to a second position. Only four degrees provide teaching content that explicitly includes the biosanitary-medical field, and none of them is an independent course either for interpreting or translation subject-matters. Through these courses, students can learn some relevant knowledge in the medical field, but it is very limited. Healthcare interpretation is usually incorporated in courses dedicated to interlinguistic communication and intercultural mediation. Specifically, six programs offer a course in community service interpretation and translation, and eight programs have courses with different names but similar teaching content. Due to the limitation of teaching hours and the variety of fields involved, the training in each area (translation and interpreting) is basically introductory and only covers essential aspects. From this it can be deduced that undergraduate training to develop the thematic subcompetence in the healthcare field is scarce and insufficient.

At the postgraduate level, the development of the strategic subcompetence is still the main training goal. Due to the more detailed education positioning 
Wang, X. \& Lázaro Gutiérrez, R. (2021). Healthcare interpreting: filling the training gap to achieve required competences. Current Trends in Translation Teaching and Learning E, 8. 124 - 153. https://doi.org/10.51287/cttle20215

at this stage, among the 14 programs listed, five are designed for conference interpreting, which means a significant dedication to the consecutive and simultaneous modalities and to strategies adapted to the formal conference environment. The other programs mainly provide courses related to the setting where interpretation is performed, rather than the modality of interpretation that needs to be used.

Similar to the offer at undergraduate level, the professional subcompetence also continues to be a relatively large part of each program, but with a different approach. At this stage, emphasis is placed on more specific aspects of the profession, such as project management, job placement, company organization, etc. It can also be observed that subjects related to deontology increase considerably at this level.

In syllabi for master's degrees, the range of language combinations is more limited, with European languages maintaining their predominant percentages. On the other hand, Chinese outnumbers Arabic quantitatively, as $35 \%$ of the master's degree programs offer it as a $B$ language. In addition, non-specific language interpreting training courses, which are dedicated to only one language and culture, such as Cultures and Civilizations of 
Wang, X. \& Lázaro Gutiérrez, R. (2021). Healthcare interpreting: filling the training gap to achieve required competences. Current Trends in Translation Teaching and Learning E, 8. 124 - 153. https://doi.org/10.51287/cttle20215

English-Speaking Countries, are practically absent, while emphasis is placed on interculturality. All programs offer courses that include this kind of contents.

Regarding the development of the thematic subcompetence, courses for interpretation in public services or intercultural mediation covering healthcare interpreting are available in half of the 14 programs, and in two of them they even accounted for $25 \%$ of the total credits (15 of 60 ECTS). However, because such courses are not usually compulsory in undergraduate education, it is still necessary to begin with basic content at the training of master's degrees, which results in a frequent overlap between the two levels of study.

Healthcare interpreting as an independent course was found at two syllabi: the Master's Degree in Medical and Health Translation of the University Jaume I and the Master's Degree in Intercultural Communication and Public Service Interpreting and Translation of the University Alcala. The first one is a program focused on the medical-healthcare field, paying more attention to translation. The working languages are Spanish and English. In addition to interpretation, medical knowledge courses are also offered, which help students acquire a comprehensive understanding of professional 
Wang, X. \& Lázaro Gutiérrez, R. (2021). Healthcare interpreting: filling the training gap to achieve required competences. Current Trends in Translation Teaching and Learning E, 8. 124 - 153. https://doi.org/10.51287/cttle20215

knowledge in the field of work. The second one concentrates on cross-cultural communication in a variety of languages. As a practice-oriented program, the curriculum is designed to focus more on the development of communication skills and crosscultural competences, and therefore less on the transfer of relevant professional domain knowledge.

Overall, although in terms of proportion, the offer of healthcare-related contents is more prominent than at the undergraduate level, it is still aimed to cover basic needs of interpreters to build relevant context knowledge. In most cases, the development of the thematic subcompetence still needs to be completed with more supporting resources.

\subsection{Non-Formal Training}

The informal training providers group is mainly made of private professional schools, associations and research groups. Government departments, NGOs and trade unions also offer courses in language, culture, intercultural and communication skills, but they are usually aimed at immigrants in order to promote their social integration.

Regarding professional schools, Trágora Formación, Estudio Sampere, Aulasic, to name a few, emphasize the development of the professional subcompetence, 
Wang, X. \& Lázaro Gutiérrez, R. (2021). Healthcare interpreting: filling the training gap to achieve required competences. Current Trends in Translation Teaching and Learning E, 8. 124 - 153. https://doi.org/10.51287/cttle20215

fixing attention on instrumental and communication skills, but also offer contents focused on specific techniques, e.g. note-taking, memory practice, etc. None of them offers training for healthcare interpreting, and related courses that can be found in their catalogue are dedicated to translation or interpretation in general, with an emphasis on specialized terminology in a combination of the most commonly used languages: English, Spanish and French. The duration of the courses vary from 90 minutes to 300 hours if the training is online.

The programs offered by associations and research groups (APTIC, Asetrad, MIRAS, Greti, etc.) are more varied and stable, but attention to the healthcare field is also almost absent. FITISPos, for example, as a group mainly dedicated to public service translation and interpreting, provides courses which cover multiple fields and has more lesser diffusion language combination options. However, of the 60 programs published on its official website, only three are related to the healthcare field. In addition, because the non-formal training is organized in the shape of short courses and workshops, the contents are mainly introductory, with the aim of offering trainees a first approach to the world of public services. 
Wang, X. \& Lázaro Gutiérrez, R. (2021). Healthcare interpreting: filling the training gap to achieve required competences. Current Trends in Translation Teaching and Learning E, 8. 124 - 153. https://doi.org/10.51287/cttle20215

To sum up, in the Spanish training offer in healthcare interpreting, taking into account both formal and non-formal training, conference interpreting is still the focus for most programs. For a healthcare interpreting learner, the development of strategic and professional subcompetences is better catered for in comparison with other subcompetences. Intercultural skills, and basic concepts about public services are also considerably present. Meanwhile, the psychophysiological subcompetence is the most disregarded since, according to Albl-Mikasa (2012), this should have been achieved before starting the training and should be developed constantly while adapting to each individual situation.

Concerning the linguistic offer, English is in the absolute predominant position due to its function as lingua franca, especially in international conferences. However, according to the date proposed by the Ministry of Inclusion, Social Security and Migration (2021), the vast majority of resident foreigners in Spain come from nonEnglish-speaking countries, such as Romania, Morocco, Italy, China, or Bulgaria, and they have a greater need to the interpretation service. Taking into account the variable educational level of immigrants, we can deduce that in the healthcare field, the preferred language with which interpreters 
Wang, X. \& Lázaro Gutiérrez, R. (2021). Healthcare interpreting: filling the training gap to achieve required competences. Current Trends in Translation Teaching and Learning E, 8. 124 - 153. https://doi.org/10.51287/cttle20215

work may not be English, but other lesser diffusion languages. Thus, to complete the training of healthcare interpreters, it is necessary to seek additional resources specific to these languages to achieve progress in the thematic subcompetence and a good knowledge of the corresponding cultural aspects related to health.

\section{CONCLUSION}

The review of curricula and syllabi that has been carried out shows that in Spain the education providers have not yet responded to the shift in market demands for interpreting training. In general, the current training gap is reflected in two main areas.

The first one is the unbalanced attention given to each subcompetence in the competency model. Most training programs are still centered on conference interpreting, focusing on the development of the strategic subcompetence and taking cognitive development, language information transfer, and the command of interpreting tools as the core of education. Courses are mostly dedicated to consecutive and simultaneous interpreting, and, although this training is also useful for future bilateral interpreters, particularly in the development of cognitive abilities, 
Wang, X. \& Lázaro Gutiérrez, R. (2021). Healthcare interpreting: filling the training gap to achieve required competences. Current Trends in Translation Teaching and Learning E, 8. 124 - 153. https://doi.org/10.51287/cttle20215

bilateral interpreting requires more cultural sensitivity and intercultural communication skills.

The professional subcompetence has not received as much attention as the previous one, but related contents are offered, with an emphasis on the acquisition of intercultural communication skills. The psychophysiological subcompetence and the healthcare thematic subcompetence are significantly less addressed. Although being an interpreter does not require the same level of knowledge as a professional practitioner (for instance, a medical doctor), building a basic framework of knowledge in the relevant field is essential for the correct understanding of the information received and the proper production of output during the interpretation process.

Secondly, there is an imbalance in the development of different language pairs. English, as the lingua franca, is the absolute leader in training programs. In Spain, if an interpreter's working language is Spanish and English, the training courses or materials they can find will basically satisfy his or her learning needs. However, if the interpreter's working language is one of lesser diffusion, which, as mentioned earlier, would be a more common case, then the likelihood that he or she will be able to find training courses is significantly reduced. Regarding 
Wang, X. \& Lázaro Gutiérrez, R. (2021). Healthcare interpreting: filling the training gap to achieve required competences. Current Trends in Translation Teaching and Learning E, 8. 124 - 153. https://doi.org/10.51287/cttle20215

training in the most spoken languages, such as English, more appropriate methods for interpreting training in public services are already being developed, for example reducing the attention paid to the cognitive aspect and placing emphasis on cultural and social factors that may affect the communicative act (Angelelli, 2020). On the other hand, for languages of lesser diffusion training is still in the most basic stage, and the focus is on activities such as compiling specific terms, trying to get basic information related to the setting in which interpreting is performed, or improving techniques for transferring messages. Besides, although some content about interpreting strategic subcompetence can be found in every program, this is still not adapted to the specificities of each language pair. Language is a vehicle for culture, so the uneven development of each language brings with it a corresponding uneven cultural development.

Filling the current training gap and establishing an efficient and integral education system is one of the decisive factors to promote the development of professionalization. In the long run, a clearer distinction should be made between conference interpretation and public service interpretation (including healthcare interpreting). Because they have different training focuses, it is necessary to avoid the development of the strategic 
Wang, X. \& Lázaro Gutiérrez, R. (2021). Healthcare interpreting: filling the training gap to achieve required competences. Current Trends in Translation Teaching and Learning E, 8. 124 - 153. https://doi.org/10.51287/cttle20215

subcompetence as the main training goal in all interpretation courses. Training providers of all stages, whether in the formal or informal education field, should consider offering more language options and culturally-based courses related to those languages in the context of local demographics. Furthermore, to actively promote interdisciplinary collaboration to provide training in the fundamentals of the field of healthcare and medicine is also a viable option, like organizing meetings with practitioners, psychologists and students to help them understand and learn to deal with physical and emotional issues that may arise in the real world of work.

However, healthcare interpreting training is just in its infancy for now, and there is still much to be done to reach the complete establishment of a training system. In the meantime, the demand for healthcare from foreigners who cannot communicate effectively with local service providers continues to exist and will likely trend upward again when population mobility resumes worldwide. Therefore, in addition to the long-term plans mentioned above, there is still a need for transitional solutions that can take effect in the short term, those that allow us to take advantage of the already available courses while looking for other remedies to reduce the training gap. 
Wang, X. \& Lázaro Gutiérrez, R. (2021). Healthcare interpreting: filling the training gap to achieve required competences. Current Trends in Translation Teaching and Learning E, 8. 124 - 153. https://doi.org/10.51287/cttle20215

In this sense, the elaboration and launch of new materials aids for languages of lesser diffusion can be one of them. On the one hand, among all the components of the interpreting competence, some can be acquired through self, independent training, while some others will require a higher level of teacher involvement and interpersonal interaction. The training gap that now exists, especially in the acquisition of thematic knowledge and cultural aspects that may affect communication, belongs to the first group, which can be acquired through support resources contrary to the other one. At the same time, such materials can also help students build a framework of knowledge quickly in advance, and thus when they follow a course, they can take advantage of the limited time to develop subcompetences of the second type, such as the practice of professional strategies by means of simulation activities. Moreover, the availability of materials aimed at languages off lesser diffusion can also reduce the imbalance of progress between students of different language combinations to a certain extent.

The scarcity of training on healthcare interpretation in Spain may have different causes. One of them can be the recent immigration phenomenon in comparison to other Western countries, which still 
Wang, X. \& Lázaro Gutiérrez, R. (2021). Healthcare interpreting: filling the training gap to achieve required competences. Current Trends in Translation Teaching and Learning E, 8. 124 - 153. https://doi.org/10.51287/cttle20215

requires social adaptation. Another and related one could be the low recognition of public service interpreting as a profession, which leads to unstable work and low pay. It is logical that those interested at first in the activity of healthcare interpreting do not want to invest a lot of time and money to receive corresponding training. Training materials, such as books, both in paper and electronic form, are characterized by their flexibility and affordability compared to courses. They mean a low costeffective investment that also covers the essential vocational training needs.

In conclusion, according to the current situation, the offer of training materials aimed at one or more languages of lesser diffusion covering specific healthcare and medicine contents, cultural aspects related health, and other that may affect communication in healthcare contexts can be a valid option to reduce the gap in healthcare interpretation training. 
Wang, X. \& Lázaro Gutiérrez, R. (2021). Healthcare interpreting: filling the training gap to achieve required competences. Current Trends in Translation Teaching and Learning E, 8. 124 - 153. https://doi.org/10.51287/cttle20215

\section{REFERENCES}

Abril Martí, M.I. (2006). La Interpretación en los Servicios Públicos: Caracterización como género, contextualización y modelos de formación. Hacia unas bases para el diseño curricular. Universidad de Granada.

Albl-Mikasa, M. (2012). The importance of being not too earnest : a process- and experience-based model of interpreter competence . In Ahrens, B., Albl-Mikasa, M., Sasse, Cl. (Eds.). Dolmetschqualität in Praxis, Lehre und Forschung : Festschrift für Sylvia Kalina (pp. 59-92). Gunter Narr Verlag.

Angelelli, C. V. (2006). Designing curriculum for healthcare interpreting education: A principles approach. In Roy, C. B. (Ed.). New Approaches to Interpreter Education (pp. 23-46). Gallaudet University Press.

Angelelli, C. V. (2020). Community/Public-service interpreting as a communicative event: A call for shifting teaching and learning foci. Translation and Translanguaging in Multilingual Contexts, 6(2), 114-130. 
Wang, X. \& Lázaro Gutiérrez, R. (2021). Healthcare interpreting: filling the training gap to achieve required competences. Current Trends in Translation Teaching and Learning E, 8. 124 - 153. https://doi.org/10.51287/cttle20215

Baigorri, J. J. (2000). La interpretación de conferencias: el nacimiento de una profesión, de París a Nuremberg. Comares.

Blignault, I., Stephanou, M., \& Barrett, C. (2009). Achieving quality in health care interpreting: Insights from interpreters. In Hale S., Ozolins U., Stern L. (Eds.). The critical link 5: Quality in interpreting - a shared responsibility (pp. 221-234). John Benjamins Publishing.

Corsellis, A. (2008). Public service interpreting: The first steps. Springer.

Cox, A., \& Lázaro Gutiérrez, R. (2016). Interpreting in the Emergency Department. How Context Matters for Practice. In Federici, F. M. (Ed.). Mediating Emergencies: Front-line Translation and Interpreting (pp. 35-58). Palgrave Macmillan.

Crezee, I. H. (2013). Introduction to healthcare for interpreters and translators. John Benjamins Publishing.

European Communities. (2008). The European qualification framework for lifelong learning. http://ecompetences.eu/wpcontent/uploads/2013/11/EQF_broch_2008_en.pdf 
Wang, X. \& Lázaro Gutiérrez, R. (2021). Healthcare interpreting: filling the training gap to achieve required competences. Current Trends in Translation Teaching and Learning E, 8. 124 - 153. https://doi.org/10.51287/cttle20215

Gile, D. (1995). Basic Concepts and Models for Interpreter and Translator Training. John Benjamins Publishing.

Hale, S. B. (2007). Community Interpreting. Palgrave Macmillan.

Herbert, J. (1952). The Interpreter's Handbook: How to Become a Conference Interpreter. Librairie de 1"Université.

Hsieh, E. (2016). Bilingual Health Communication: Working with Interpreters in Cross-Cultural Care. Routledge.

Kaczmarek, Ł. (2010). Modelling competence in community interpreting: Expectancies, impressions and implications for accreditation. [PhD thesis]. University of Manchester.

Kalina, S. (2002). Interpreters as Professionals. Across Languages and Cultures, 3(2). 169-187.

Keiser, W. (1978) Selection and Training of Conference Interpreters. In Gerver, D. \& Sinaiko, H.W. (Eds.). Language Interpretation and Communication. Springer. 
Wang, X. \& Lázaro Gutiérrez, R. (2021). Healthcare interpreting: filling the training gap to achieve required competences. Current Trends in Translation Teaching and Learning E, 8. 124 - 153. https://doi.org/10.51287/cttle20215

Kelly, D. (2002). Un modelo de competencia traductora: bases para el diseño curricular. Puentes, (1), 9-20.

Kelly, D. (2005). A handbook for translator trainers. Routledge.

Lázaro Gutiérrez, R. (2012). La interpretación en el ámbito sanitario. Estudio de la asimetría en consultas médicas. Editorial Académica Española.

Ministerio de Inclusión, Seguridad Social y Migraciones. (2021). Extranjeros con certificado de registro o tarjeta de residencia en vigor. A 31 de diciembre de 2020.

https://public.tableau.com/views/Residentes_31122 0/Infografia?\%3AshowVizHome $=$ no\&\%3Aembed $=$ true\#6

NSW Department of Health. (2017). Standard Procedures for Working with Health Care Interpreters. https://www1.health.nsw.gov.au/pds/ActivePDSDoc uments/PD2017_044.pdf

Peng, Y.P. (2018). Yi Xue Qing Jing Kua Wen Hua Jiao Ji Neng Li Yan Jiu. [Research on Intercultural Communication Competence In Healthcare Contexts]. Hebei People's Publishing House 
Wang, X. \& Lázaro Gutiérrez, R. (2021). Healthcare interpreting: filling the training gap to achieve required competences. Current Trends in Translation Teaching and Learning E, 8. 124 - 153. https://doi.org/10.51287/cttle20215

Pöchhacker, F. (2000). The Community Interpreter's Task: Self-Perception and Provider Views. In Roberts, R.P., Carr, S.E., Abraham, D. \& Dufour, A. (Eds.). The Critical Link 2: Interpreters in the Community. John Benjamins Publishing.

Remael, A., Cambridge, J., Fuhrer, U., Salaets, H. \& Valero-Garcés, C. (2018). Public service interpreting: minimally required competence in terms of knowledge, skills and attitudes. http://www.enpsit.org/training-accreditation.html

Sanz, J. (1931). Le travail et les aptitudes des interpretes parlementaires. Anals d'orientació profesional, año 4, n4. pp.303-318. 